\title{
EDITORIAL
}

\section{Premature vascular ageing in cystic fibrosis}

\author{
W. MacNee
}

I $\mathrm{t}$ is increasingly recognised that chronic inflammatory disorders of the lungs, such as chronic obstructive pulmonary disease (COPD), and other organs, such as rheumatoid arthritis, are associated with systemic effects that result in comorbidities [1, 2]. Cystic fibrosis (CF) has also been shown to have systemic effects, for example loss of muscle mass and decreased bone density associated with a systemic inflammatory response [3]. A further systemic effect of chronic inflammatory conditions, such as COPD and rheumatoid arthritis, is the development of systemic vascular abnormalities with resultant cardiovascular comorbidity $[4,5]$, which has important adverse effects on morbidity and mortality in these conditions. Many of these comorbid conditions are a feature of ageing, and it has been suggested that the presence of these comorbidities reflects an accelerated ageing process in conditions such as COPD [6].

Increased central arterial stiffening is a hallmark of the ageing process even in healthy individuals without any cardiovascular disease [7], and is a consequence in many disease states, such as diabetes, arteriosclerosis, chronic renal impairment [8] and COPD [9]. Arterial stiffening is also a marker of increased cardiovascular risk, including myocardial infarction, heart failure and total mortality [10]. There is very little clinical or epidemiological data linking increased cardiovascular risk in CF patients, perhaps due to the shortened lifespan in these patients or to protection against the development of cardiovascular disease due to a favourable lipid and blood pressure profile in these patients [11]. In this issue of the European Respiratory Journal, Hull et al. [12] suggest that the presence of systemic inflammation in CF patients may lead to vascular changes, specifically an increase in vascular stiffness, which may predict future increased cardiovascular risk that might become apparent with the increase in longevity in these patients.

In a cross-sectional study, 50 adult patients with $\mathrm{CF}$ and a mean \pm SD age of $28.0 \pm 8.2$ yrs had their arterial stiffness measured by aortic (carotid-femoral) and brachial (carotidradial) pulse wave velocity (PWV) [12]. In addition, the central arterial wave form was analysed to calculate the augmentation index (AIx), which is another measure of arterial stiffness [13]. Measurements in CF patients were compared with 26 healthy, age-matched controls. The study showed that the AIx was significantly greater in CF patients than in controls, after adjustment for most of the known potential confounders, such as age, sex, height and peripheral mean arterial pressure [12].

CORRESPONDENCE: W. MacNee, ELEGI Colt Laboratories, MRC Centre for Inflammation Research, The Queen's Medical Research Institute, 47 Little France Crescent, Edinburgh, EH16 4TJ, UK. E-mail:w.macnee@ed.ac.uk
AIx was related to age in both control subjects and patients, and was greater in patients than controls in each age range. In addition, AIx was greater in patients with CF-related diabetes compared to patients with non-CF-related diabetes. However, PWV was not different between controls and patients, although aortic PWV was greater in the subgroup of CFrelated diabetic patients, than in either the non-CF diabetic patients or controls. HuLL et al. [12] suggest that these changes in aortic AIx reflect increased arterial stiffness and represent accelerated arterial ageing in CF patients.

Arterial stiffness can be assessed using a variety of different techniques [13]. However, PWV is currently considered the "gold standard" measurement of arterial stiffness. It measures the speed at which the pressure wave form propagates along the segment of the arterial tree; the stiffer the vessel, the faster the wave travels. There is a curve-linear relationship between age and the aortic PWV; thus, age-related changes in aortic PWV are less marked in younger subjects and become increasingly prominent after 50 yrs of age [14]. The AIx provides a composite measure of wave reflection and systemic arterial stiffness. There is a gradual rise in AIx with age, but again the relationship to the age is non-linear, in that greater changes are seen with age in younger individuals than after 55 yrs of age where the AIx changes very little [15]. Thus, the dissociation of effects of CF on AIx and PWV reported in the study by HulL et al. [12] may be expected, since AIx is considered more sensitive to change at a young age than PWV. However, the measurement of AIx is not without difficulties. AIx not only reflects arterial stiffness but is also influenced by a number of factors, including left ventricular ejection fraction, PWV, timing of reflection, arterial tone, structure at peripheral reflecting sites, blood pressure, age and heart rate. There is also concern over the accuracy and validity of central AIx derived from the analysis of a peripheral pulse wave form [13]. There is a significant linear relationship between AIx and heart rate [16] and the CF patients had higher heart rates than controls. However, in the study by Hull et al. [12], aortic index was corrected for heart rate and adjusted for age and blood pressure but not for some other confounders.

The changes in aortic stiffness in the CF patients in the study by Hull et al. [12] were also not explained by traditional cardiovascular risk factors, such as plasma lipids, increased blood pressure, physical activity or smoking history. A significant relationship was, however, found between $\log C$ reactive protein (CRP) and $\mathrm{AIx}$, and in a multiple regression analysis, age, height and log CRP were predictive of AIx and accounted for $50 \%$ total variance in AIx. Hull et al. [12] suggest that systemic inflammation, which is associated with increased cardiovascular risk in various populations [17], has an effect on both endothelial function and arterial stiffness. Aortic PWV 
has been shown to be related to the level of systemic inflammation even in healthy individuals [18]. However, the mechanism relating arterial stiffness in CF may be more complicated. Vascular stiffening develops from a complex interaction between stable and dynamic changes involving structural and cellular elements in the vessel wall [8]. Structural components of the arterial wall, mainly collagen/ elastin, together with the transmural pressure are considered to be major determinants of vessel stiffness. These structural components in the arterial wall undergo changes with ageing, such as alteration of the ratio of elastin/collagen and other matrix proteins [19]. Endogenous circulating enzymes, such as elastase and matrix metalloproteases (MMP), can break down elastin and collagen, and it is interesting that circulating MMP-9 levels correlate with PWV in hypertensive subjects [20]. Increased circulating MMP-9 levels have also been related to osteoporosis in patients with COPD [21] and there is a relationship between arterial stiffness and osteoporosis in COPD [22]. Thus, increased systemic proteolytic activity could also be a mechanism for the increased arterial stiffness in CF. Systemic inflammation may also affect endothelial function, which also influences arterial stiffness [8, 23]. Vascular smooth muscle also regulates vessel stiffness and there are a number of locally derived and circulating factors, including nitric oxide, endothelin-1 and the natriuretic peptides, which contribute to regulation of large arterial stiffness. Changes in the balance between these factors and in particular a reduction in nitric oxide production may result in arterial stiffening [8]. Thus, there are several mechanisms by which arterial stiffness could develop in chronic inflammatory conditions such as CF.

The implication of the finding of increased arterial stiffness in CF patients and the impact of increased arterial stiffness in a young population on future outcomes is not known. Longitudinal studies are required to determine the relevance of the findings of increased arterial stiffness on future cardiovascular outcome in these patients. However, the study by Hull et al. [12] does suggest the potential for increased cardiovascular risk in these patients, which may become more apparent as the lifespan of $\mathrm{CF}$ patients is prolonged. Measurements of arterial stiffness are increasingly used as a marker of assessing vascular function. Further elucidation of the mechanisms that result in systemic vascular stiffness in chronic inflammatory diseases, such as $\mathrm{CF}$, will aid more specifically targeted therapeutic interventions for this aspect of the disease.

\section{STATEMENT OF INTEREST}

A statement of interest for $\mathrm{W}$. MacNee can be found at www.erj. ersjournals.com $/ \mathrm{misc} /$ statements.dtl

\section{REFERENCES}

1 Fabbri LM, Luppi F, Beghé B, et al. Complex chronic comorbidities of COPD. Eur Respir J 2008; 31: 204-212.

2 Gabriel SE. Why do people with rheumatoid arthritis die prematurely? Ann Rheum Dis 2008; 67: Suppl. 3, iii30-34.
3 Ionescu AA, Nixon LS, Evans WD, et al. Bone density, body composition and inflammatory status in cystic fibrosis. Am J Respir Crit Care Med 2002; 162: 789-794.

4 Sokka T, Abelson B, Pincus T. Mortality in rheumatoid arthritis: 2008 update. Clin Exp Rheumatol 2008; 5: Suppl. 51, s35-s61.

5 MacNee W, Maclay J, McAllister D. Cardiovascular injury and repair in chronic obstructive pulmonary disease. Proc Am Thorac Soc 2008; 5: 824-833.

6 MacNee W. Accelerated lung aging: a novel pathogenic mechanism of chronic obstructive pulmonary disease (COPD). Biochem Soc Trans 2009; 37: 819-823.

7 Vaitkevicius P, Fleg J, Ingel J, et al. Effects of age and the aerobic capacity on arterial stiffness in health adults. Circulation 1993; 88: 1456-1462.

8 Zieman SJ, Melenovsky V, Kass DA. Mechanisms, pathophysiology and therapy of arterial stiffness. Arterioscler Thromb Vasc Biol 2005; 25: 932-943.

9 Maclay JD, McAllister DA, Mills NL, et al. Vascular dysfunction in chronic obstructive pulmonary disease. Am J Respir Crit Care Med 2009; 180: 513-520.

10 Safar ME, Levy BI, Struijker-Boutier H. Current perspectives on arterial stiffness and pulse pressure in hypertension and cardiovascular diseases. Circulation 2003; 107: 2864-2869.

11 Schwarzenberg SJ, Thomas W, Olsen TW, et al. Microvascular complications in cystic fibrosis-related diabetes. Diabetes Care 2007; 30: 1056-1061.

12 Hull JH, Garrod R, Ho TB, et al. Increased augmentation index in patients with cystic fibrosis. Eur Respir J 2009; 34; 1322-1328.

13 Hamilton PK, Lockhart CJ, Quinn CE, et al. Arterial stiffness: clinical relevance, measurement and treatment. Clin Sci 2007; 113: 157-170.

14 McEniery CM, Wilkinson IB, Avolio AP. Age, hypertension and arterial function. Clin Exp Pharmacol Physiol 2007; 34: 665-671.

15 McEniery CM, Wiseman IR, Quasem A, et al. Normal vascular aging. Differential effects on wave reflection and aortic pulse wave velocity: the Anglo-Cardiff Collaborative Trial (ACCT1). J Am Coll Cardiol 2005; 46: 1753-1760.

16 Wilkinson IB, McCallum $\mathrm{H}$, Flint L, et al. Influence of heart rate augmentation index and central arterial pressure in humans. Ann Physiolog 2007; 525: 263-270.

17 Ridker PM, Cushman M, Stampfer MJ, et al. Inflammation, aspirin and the risk from cardiovascular disease in apparently healthy men. New Eng J Med 1997; 336: 973-979.

18 Yasmin, McEniery CM, Wallace S, et al. C-reactive protein is associated with arterial stiffness in apparently healthy individuals. Arteriosceler Thromb Vasc Biol 2004; 24: 969-974.

19 Greenwald SE. Ageing of conduit arteries. J Pathol 2007; 211: 157-172.

20 Yasmin, McEniery CM, Wallace S, et al. Matrix mettalloprotease-9 (MMP-9), MMP-2 and serum elastase activity are associated with systemic hypertension and arterial stiffness. Artheroscler Thomb Vasc Biol 2005; 25: 372.

21 Bolton $\mathrm{CE}$, Stone MD, Edwards $\mathrm{PH}$, et al. Circulating matrix metalloproteinase-9 and osteoporosis in patients with chronic obstructive pulmonary disease. Chronic Respir Dis 2009; 6: 81-87.

22 Sabit R, Bolton CE, Edwards PH, et al. Arterial stiffness and osteoporosis in chronic obstructive pulmonary disease. Am J Respir Crit Care Med 2007; 175: 1259-1265.

23 Maki-Petaja KM, Wilkinson IB. Anti-inflammatory drugs and statins for arterial stiffness reduction. Curr Pharm Des 2009; 15: 290-303. 